\title{
Development of digital simulation on the basis of technologies of virtual and augmented reality $^{\mathrm{a}}$
}

\author{
Alexander Gren ${ }^{1}$, Benjamin Jamarillo ${ }^{2}$, Vladislav $\mathrm{Kiev}^{2}$, Nikolai Shabrov ${ }^{2 *}$, and Dmitry \\ Vasiliev $^{2}$ \\ ${ }^{1}$ Emuge-Franken, 91207 Nürnberger Straße 96-100, Germany \\ ${ }^{2}$ Peter the Great St. Petersburg Polytechnic University, 195251 Polytechnicheskaya st. 29, Russian \\ Federation
}

\begin{abstract}
The world scientific and industrial community enters presently a new phase of its development. Suffice to mention such key developments as the strategy of development of "Industry 4.0" for German manufacturers [1], two American concepts: "Industrial Internet" [2] and "Internet of things" [3]. The work on artificial intellect [4] released in 2003 laid the bases for industrial development of systems with artificial intellect, while a wide discussion on the Fourth industrial revolution [5] as a continuation of the concept of "The second industrial era" [6] was initiated in 2016 at the World economical forum. The implementation of these industrial concepts brings about a high level of competition and, as a result, searching new technologies of manufacturing competitive produce. The manufacture of competitive produce is closely connected with the problems of apprehension a great volume of information connected with the results of designing, simulation, marketing and sales of the factories' produce. The program Industry 4.0 implies a wide use of the cutting-edge digital technologies and, particularly, the technologies of virtual and augmented reality.
\end{abstract}

The point at issue is the expansion of technologies of digital engineering in the direction of technologies of virtual engineering with an active application of multi-screen systems of virtual environment CAVE 3D (Computer Aided Virtual Environment) and technologies of augmented reality (Fig. 1).

a The authors express their gratitude to Russian Science Foundation (RSF) for supporting investigations in the framework of grant No.18-11-00245

*Corresponding author: shabrov@rwwws.ru 


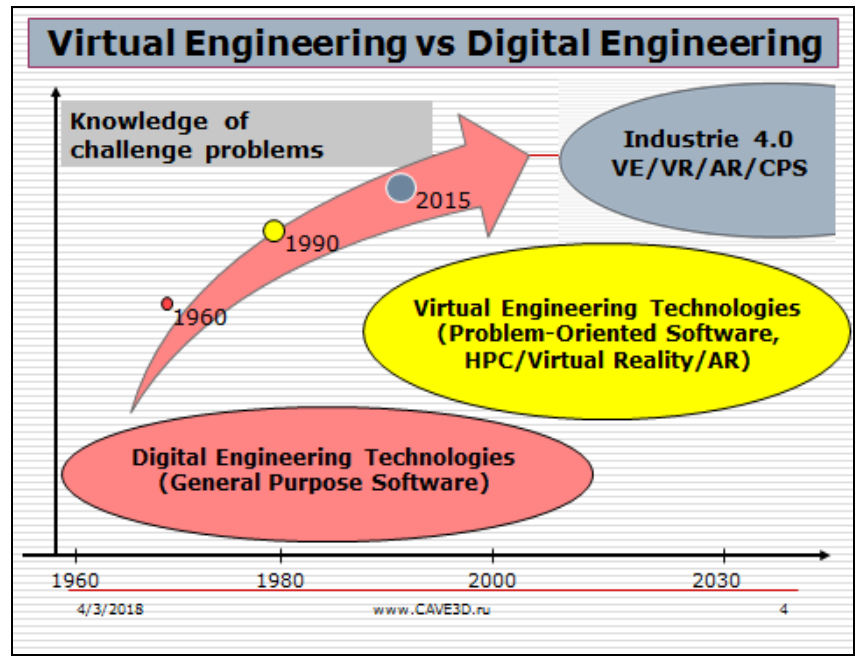

Fig. 1. Stages of engineering technologies development.

There are two types of predictive simulation problems: ordinary and extraordinary. There is a guarantee of getting solution by means of commercial multi-purpose software code for ordinary problems, which is perfectly well provided by the set of models and numerical diagrams of this code. This type of simulation is characteristic for the stage of development of the industrial revolution Industry 3.0. The present time demands solving call problems for creating the breakthrough technologies to provide development of the present-day industry. This means that the solution of science extraordinary problems is on the agenda, which demands the new approaches at all stages of solution simulation.

However, the latest versions of commercial software code are in arrears of the advanced frontiers of science by $10+$ years immediately after release. In view of this fact it is impossible to provide solution of extraordinary problems by the set of physical and mathematical models of commercial multi-purpose code owing to inadequacy of the used or due to ineffective scaling of calculations (Fig.2). In order to solve the extraordinary problems, it is necessary to develop the unique physical models and equations of the object state, development of numerical diagrams of solving equations and, as a result, building the problem-oriented in-house dedicated software system with all attributes appropriate of the modern system, including pre- and post-processor, on-line help, means of forming online report and analyzing simulation results in in-situ mode on the basis of virtual environment systems. 


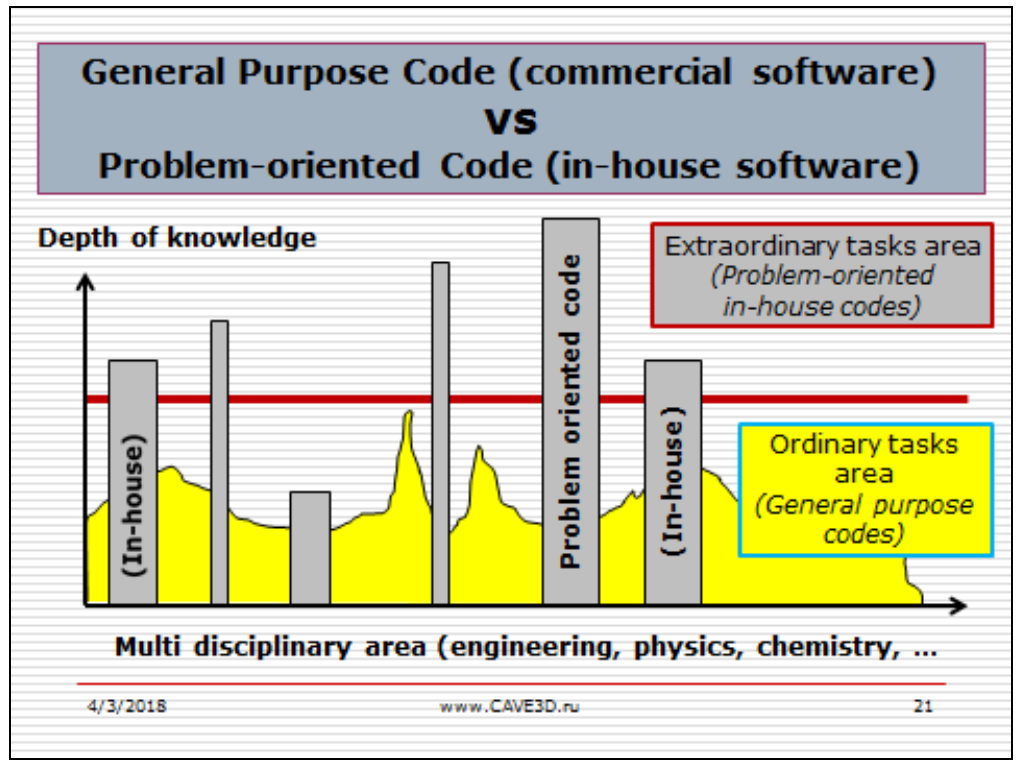

Fig. 2. Level of depth of jumping into problem for commercial code and problem-oriented in-house code.

The stage of development of engineering technologies in the program Industry 4.0 is characterized by conducting analysis of results of predictive simulation using the means of systems CAVE 3D [7], which are the decision-making centers in the context of analysis of results (Fig. 3).

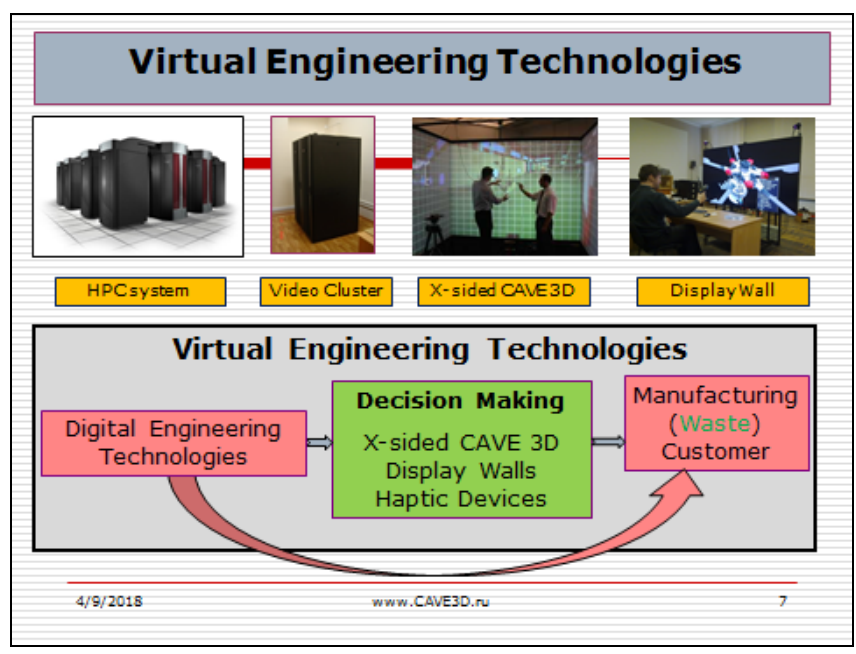

Fig. 3. Place of decisions-making center in general procedure of virtual engineering technologies.

Recently, reasonable attention is paid to the problem of analyzing results of predictive simulation in HPC systems in in-situ (on-the-fly) mode. Two circumstances contribute thereto. First of all, the emergence of hardware in the market, which helps obtain a highquality image and, secondly, an acute necessity of "on-the-fly" analyzing results with the aim of monitoring and correcting the progress of making calculations in HPC systems. Particularly, it is applicable to the problems based on multi-scale and interdisciplinary models (turbulent combustion processes, etc.), which demand extensive resources of HPC 
systems. Thus, a chance has appeared recently to adequately improve the process of analyzing results of predictive simulation in HPC systems in "on-the-fly" mode with the use of virtual environment systems.

The technologies of virtual engineering feature significant advantages over digital engineering technologies, which dominated prior to beginning of the industrial revolution Industry 4.0 stage. The main advantage consists in a significant shortage of industrial waste since a comprehensive control of results of $3 \mathrm{D}$ model simulation in virtual environment system CAVE 3D takes place prior to beginning the article production (Fig. 4).

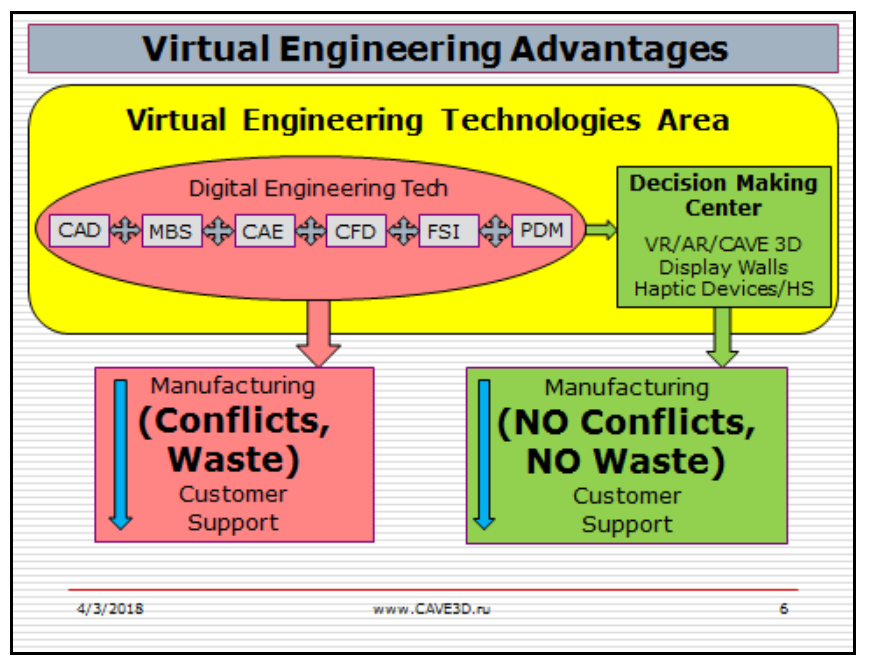

Fig. 4. Advantages of virtual engineering technologies against digital engineering technologies.

At the same time the growing level of high competition in the industry stimulates the development agencies and manufactures of the machine-building produce get across the advantages of a particular product to a buyer of the machine-building produce quickly and in an understandable fashion. Therefore, a growing interest is observable presently to the developments of virtual technical manuals on the basis of augmented-reality technologies.

A virtual technical manual has been created together by EMUGE-FRANKEN (Germany) and Peter the Great St. Petersburg Polytechnic University at the chair of "Computer technologies in machine-building". EMUGE-FRANKEN, the German company boasting more than 90 years of experience, develops and manufactures the precision tools as well as high-accuracy высокоточную tooling equipment for fastening the parts to be machined during machining at the industrial enterprises. Creation of such tooling-related solutions in the technology of cutting and milling thread makes a basis of the business.

An animated model of screwed-shank chuck HF20 assembly has been selected as an "augmented reality" (Fig.5). The company's experience shows that this product is needed by the companies on the Russian market dealing with metals processing by drilling and threads generation. 


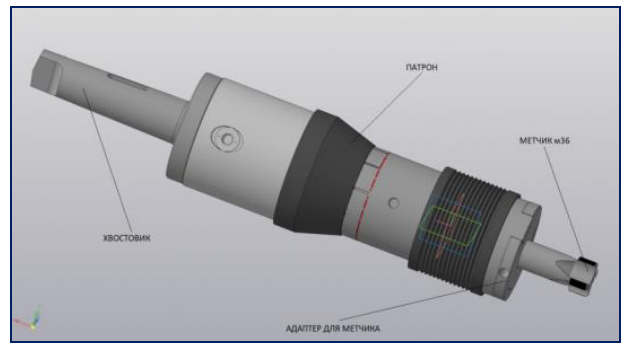

Fig. 4. Building 3D model of chuck holder in CAD system KOMPAS 3D.

The augmented reality makes it possible to better understand such advantages of the product as: possibility of shank replacement with the shank of the required shape (standard and size) and adapt the screwed-shank chuck to different variants of machine-tool spindle, possibility of changing adapter for a required task, e.g., drilling hole or cutting thread. The 3D interactive models and augmented-reality animations provide for a new level of training, understanding documents by the experts or users.

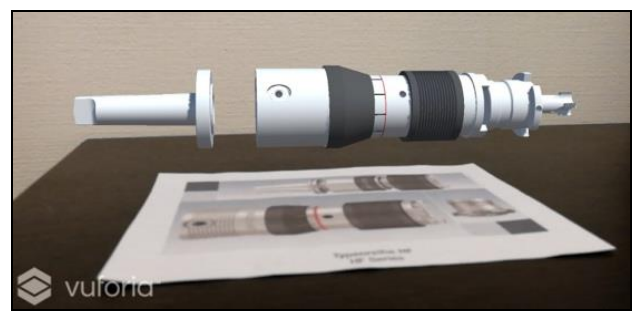

(a)

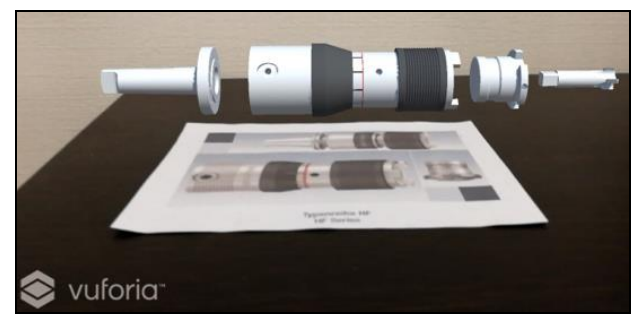

(b)

Fig. 6. Final view of process of assembly (a) - disassembly (b) of CAD model of chuck holder. Reproduction is made from application for mobile phones android.

An image of the screwed-shank chuck in the catalog is used as "Target". In case the image comes in view of the camera of tablet or Smartphone the animation of sequence of assembly of the screwed-shank chuck, adapter and tap will be output to the screen of a device (Fig. 7).

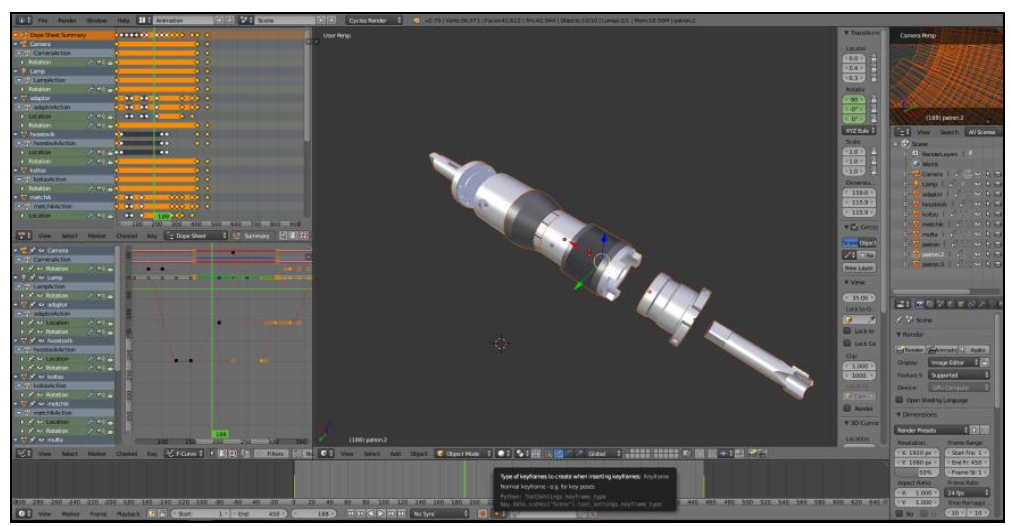

Fig. 7. Development of scenario of animation of process of assembly - disassembly of CAD model of chuck holder. 
The "Unity" software with its extension "Vuforia" is used for augmented reality, where the brand for chuck reproduction from telephone application has been developed for the first time. The chuck has been imported from "Blender" software with the required corrections made (chuck size, color, etc.). An application for the telephone and tablet has been made in the final process by means of "Android studio" software. In case of directing a tablet to the brand an animated 3D model of the chuck holder will appear on the screen. The model has been thoroughly elaborated and optimized for real-time demonstration in mobile devices, moving around the brand it is possible to visualize the chuck from different sides of viewing.

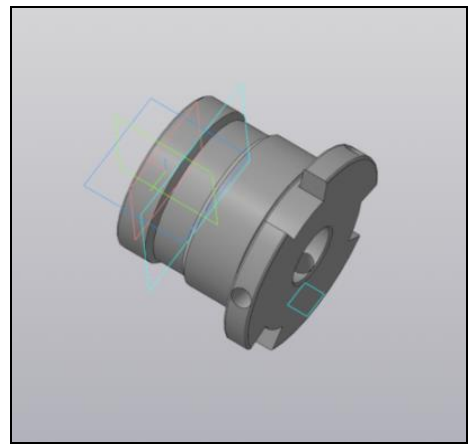

(a)

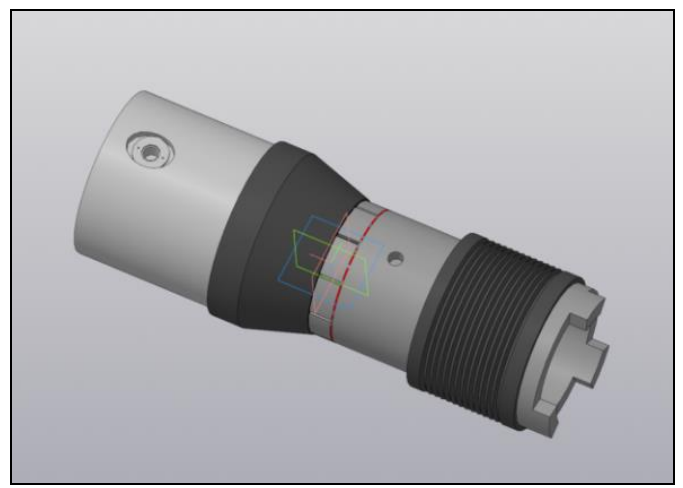

(c)

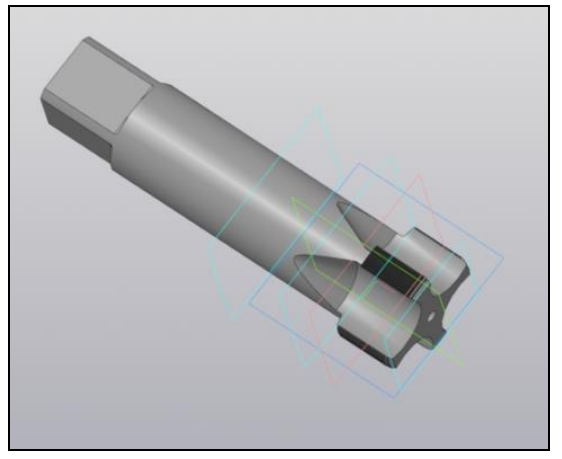

(b)

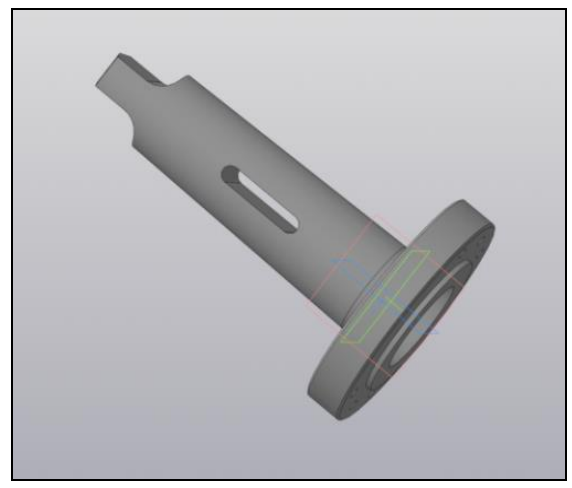

(d)

Fig. 8. Chuck holder components: $\mathrm{a}$ - adapter for tap, $\mathrm{b}$ - tap, $\mathrm{c}$ - chuck body, $\mathrm{d}-$ shank.

The augmented reality in this project makes it possible to show the sequence of assembly from the chuck parts (Fig. 8) and show operation of the screwed-shank chuck making it in the way customary and comprehensible for human-being having a Smartphone or a tablet and the company's catalog at hand only.

It should be noted that the growing application of technologies of virtual and augmented reality in modern engineering at all stages of designing and analysis is a world-wide trend of development of the modern digital technologies. 


\section{References}

1. H. Kagermann, W. Wahlster, J. Helbig, Recommendations for implementing the strategic initiative INDUSTRIE 4.0., Industrie 4.0. Working Group [online], Available at: http://www.acatech.de/fileadmin/user_upload/Baumstruktur_nach_Website/Acatech/roo t/de/Material_fuer_Sonderseiten/Industrie_4.0/Final_report_Industrie_4.0_accessible.pdf (2013)

2. P. C. Evans, M. Annunziata, Industrial Internet: Pushing the Boundaries of Minds and Machines [online], Available at: https://www.ge.com/docs/chapters/Industrial_Internet. pdf (2012)

3. M. Swan, J. Sens. Actuator Netw., 1 (2012)

4. S. J. Russel, P. Norvig, Artificial Intelligence: A Modern Approach (Prentice Hall, New Jersey, 2003)

5. K. Schwab, The Fourth Industrial Revolution: what it means, how to respond, World Economic Forum [online], Available at: https://www.weforum.org/agenda/2016/01/t he-fourth-industrial-revolution-what-it-means-and-how-to-respond/ (2016)

6. E. Brynjolfsson, A. McAfee, The Second Machine Age: Work, Progress and Prosperity in a Time of Brilliant Technologies (W.W. Norton \& Company, New York, 2014)

7. The High-Performance Computing Center Stuttgart [online], Available at: $\underline{\text { http://hlrs.de }}$ (2018) 